\title{
Novas espécies de Staurogyne Wall. (Acanthaceae) para o Brasil ${ }^{1}$
}

\author{
DENISE MONTE BRAZ ${ }^{2,4}$ e REINALDO MONTEIRO ${ }^{3}$
}

(recebido: 18 de agosto de 2005; aceito: 28 de setembro de 2006)

\begin{abstract}
New species of Staurogyne Wall. (Acanthaceae) from Brazil). The genus Staurogyne Wall. comprises about 140 tropical species, and in the Neotropics 28 species are recognized, especially found in preserved forested areas. A recent revision of the genus for the Americas revealed four new species in Brazil, which are here described. The new taxa are known from Goiás, Minas Gerais, Espírito Santo, São Paulo, Rio de Janeiro, Paraná and Santa Catarina States, three of them occurring in the Atlantic Rain Forest, and one in the gallery forests of the cerrado domain.
\end{abstract}

Key words - Acanthaceae, Neotropics, Staurogyne, taxonomy

RESUMO - (Novas espécies de Staurogyne Wall. (Acanthaceae) para o Brasil). O gênero Staurogyne Wall. reúne cerca de 140 espécies tropicais, com 28 destas reconhecidas para os neotrópicos, encontradas principalmente em áreas florestais preservadas. A revisão atualizada do gênero para as Américas revelou quatro espécies inéditas para o território brasileiro, aqui descritas. Os novos táxons são conhecidos para os Estados de Goiás, Minas Gerais, Espírito Santo, São Paulo, Rio de Janeiro, Paraná e Santa Catarina, três na Floresta Pluvial Atlântica, e uma nas matas de galeria, nos domínios do cerrado.

Palavras-chave - Acanthaceae, região neotropical, Staurogyne, taxonomia

\section{Introdução}

O gênero Staurogyne Wall. compreende cerca de 140 espécies distribuídas nos trópicos de todo o mundo (Champluvier 1991), com 28 destas ocorrendo nas Américas. Para o Brasil são reconhecidas 27 espécies, encontradas principalmente sob vegetação florestal preservada e próximas a cursos d'água, com diversas ocorrendo nas Florestas Amazônica e Atlântica e algumas nos domínios do cerrado, restritas às matas de galeria (Braz \& Monteiro 2005).

Staurogyne é reconhecido, dentre as Acanthaceae, pelas flores com cálice de segmentos desiguais, sendo o segmento posterior maior que os demais, um par de segmentos anterior de tamanho intermediário, e um par lateral menor que os demais, pelos quatro estames didínamos, inseridos na base da corola, com anteras bitecas e um estaminódio entre o par de estames posterior, e pelas cápsulas geralmente com sementes numerosas e retináculo ausente. A corola é infundibuliforme a sub-bilabiada, de coloração branca

1. Parte da tese de doutoramento de D.M. Braz. Programa de Pós-Graduação em Biologia Vegetal da Universidade Estadual Paulista - Unesp, Rio Claro, SP.

2. Universidade Federal Rural do Rio de Janeiro, Departamento de Botânica, Caixa Postal 74.541, 23890-000 Seropédica, RJ, Brasil.

3. Universidade Estadual Paulista "Júlio de Mesquita Filho", Instituto de Biociências, Departamento de Botânica, Caixa Postal 199, 13506-900 Rio Claro, SP, Brasil.

4. Autor para correspondência:dmbraz@ufrrj.br ou lilás, freqüentemente com mácula vinácea na abertura da garganta, ou é tubulosa e vermelha ou amarela (Braz \& Monteiro 2005), caracterizando as síndromes de melitofilia e ornitofilia respectivamente. As formas e colorações da corola estão dentre as principais variações na morfologia floral das espécies neotropicais, que se apresenta relativamente uniforme nos demais aspectos.

Durante a revisão taxonômica de Staurogyne para a região neotropical foram examinadas as coleções, incluindo os materiais tipo, de 51 herbários nacionais e estrangeiros que continham espécimes do gênero. Esse estudo revelou quatro novas espécies de Staurogyne para o Brasil, as quais são agora descritas e ilustradas, três destas caracterizadas pelas flores tipicamente melitófilas e encontradas na Floresta Atlântica, e uma espécie ornitófila das matas de galeria, em áreas de cerrado. São apresentadas tabelas comparativas para diferenciação das espécies mais próximas.

\section{Resultados e Discussão}

Staurogyne alba D.M. Braz \& R. Monteiro, sp. nov. Tipo: BRASIL. Paraná: Morretes, Véu de Noiva, "flores alvacentas; interior da mata pluvial", 21-VII-1985, $J$. Cordeiro \& J.M. Silva 108 (holótipo MBM).

Figura 1

Ab omnibus speciebus generis pilis glandulosis tantum corolla et fructu, inflorescentia terminali elongata et axillaribus strictis capituliformis, bracteis foliaceis ellipticis vel lanceolato-elipticis venatione 
pinnata, floribus subsessilibus corolla infundibuliformi elongata $(10,4-15,2 \mathrm{~mm})$ differt.

Ervas eretas, $30-70 \mathrm{~cm}$ alt., caule raramente ramificado, com tricomas simples esparsos ou glabrescente. Pecíolo 1,0-3,1 cm compr.; lâmina 5,2-11,0 × 2,0-4,8 cm, elíptica a elíptico-ovada, ápice acuminado a agudo, base abruptamente cuneada a cuneada, membranácea a subcartácea, face adaxial glabra, abaxial com raros tricomas simples restritos às nervuras. Inflorescência racemo espiciforme terminal e 2-4 pares axilares, com flores congestas, terminal cilíndrico, 2,5-4,5 cm compr., pedúnculo $0,5-2,0 \mathrm{~cm}$ compr., axilares subcapitados, 0,3-1,5 cm compr., pedúnculo $0,1-0,8 \mathrm{~cm}$ compr., com tricomas simples densos na raque; brácteas e bractéolas foliáceas, verdeescuras, externamente com tricomas simples esparsos, bráctea 5,0-11,7 × 2,0-6,5 mm, elípticas, ápice agudo a acuminado, base aguda a cuneada, 1-nérvea; bractéolas 3,7-7,0 $\times 0,7-1,8 \mathrm{~mm}$, lanceoladas a obovado-lanceoladas, ápice agudo a subobtuso, base aguda. Pedicelo 1,0-1,8 mm compr.; cálice esverdeado, externamente com tricomas simples esparsos, raramente tricomas glandulosos nos botões florais, às vezes ciliado, segmento posterior 9,0-14,2 × 2,9-6,3 mm, elíptico a obovado- elíptico, ápice agudo a acuminado, (3)5-nérveo, par lateral 7,1-10,5 × 0,4-1,3 mm, linear-lanceolado, par anterior $8,5-12,0 \times 1,3-2,6 \mathrm{~mm}$, linear a lanceolado; corola branca, infundibuliforme a sub-bilabiada, 10,4-15,2 mm compr., 3,0-6,0 mm diâm. na garganta, lobos posteriores 2,2-4,0 mm compr., oblongos, laterais 2,9-4,6 mm compr., oblongos a subobovados, anterior 3,1-4,7 mm compr., suborbicular, ápice levemente emarginado, com tricomas simples e glandulosos esparsos externa e internamente; estames anteriores 4,9-6,0 $\mathrm{mm}$ compr., posteriores 4,0-5,0 $\mathrm{mm}$, geralmente com tricomas glandulosos esparsos; estaminódio 1,4-1,9 mm compr., ereto, ápice anteriforme, geralmente inserido na mesma altura dos estames posteriores; anteras com tecas suborbiculares, conectivo dilatado no dorso, 0,9-1,1 mm compr.; óvulos 15-19 por lóculo; estilete 7,0-8,3 mm compr., lobo posterior do estigma côncavo a bipartido, 0,5-0,8 mm compr., anterior 0,8-1,2 mm compr., oblongo. Cápsula cilíndrica a subcônica, 8,5-9,0 × 3,0-3,2 mm, externamente com tricomas glandulosos esparsos; sementes 15-19 por valva.

Material adicional examinado: BRASIL. PARANÁ: Campina Grande do Sul, Morro Camapuã, 24-X-2000, J. Cordeiro et al. 1792 (MBM); Ipiranga, Serra do

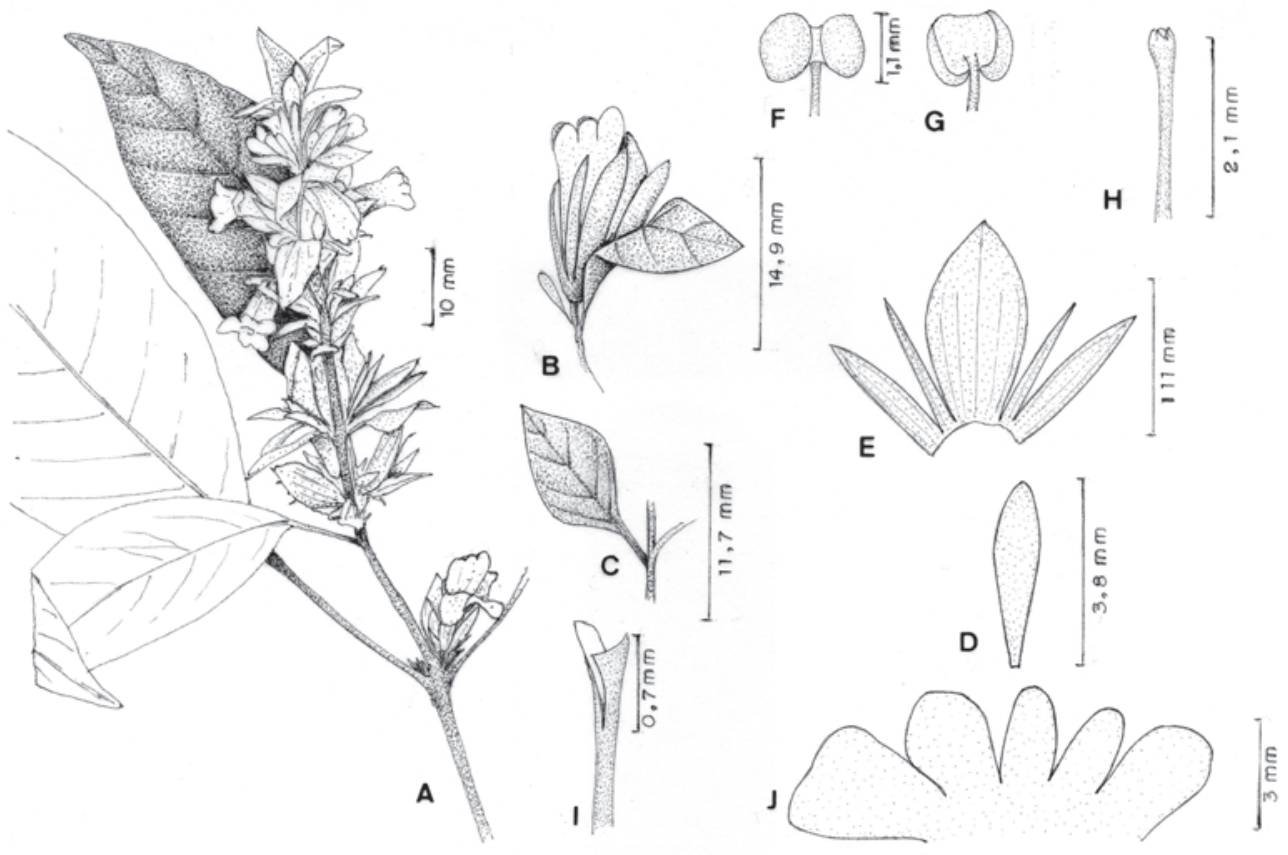

Figura 1. Staurogyne alba D.M. Braz \& R. Monteiro. A. Ramo florido. B. Flor isolada. C. Bráctea. D. Bractéola. E. Cálice seccionado em vista externa. F. Antera em vista frontal. G. Antera em vista dorsal. H. Estaminódio. I. Estigma em vista lateral. J. Lobos da corola aberta. (A-C, F-G - Jonsson 833; E, I-Dusén 6741; D, H - Cordeiro \& Silva 108).

Figure 1. Staurogyne alba D.M. Braz \& R. Monteiro. A. Flowering stem. B. Flower. C. Bract. D. Bracteole. E. Open calyx in external view. F. Anther in frontal view. G. Anther in dorsal view. H. Staminode. I. Stigma in lateral view. J. Open corolla lobes. (A-C, F-G - Jonsson 833; E, I - Dusén 6741; D, H - Cordeiro \& Silva 108). 
Mar, 19-IX-1908, P. Dusén 6741 (F, LE); Ipiranga, 23-VIII-1914, Jonsson 833 (F, K, LE); Morretes, Rio Bromado, 13-IX-1979, G. Hatschbach \& Kasper 42502 (MBM). SANTA Catarina: Garuva, Monte Cristo, 8-X-1960, R. Reitz \& Klein 10122 (L, MBM).

Staurogyne alba é restrita aos estados do Paraná e Santa Catarina, ocorrendo geralmente em altitudes elevadas no Paraná, acima dos $800 \mathrm{~m}$ de altitude. Foi coletada com flores principalmente nos meses de julho a setembro e com frutos de setembro a outubro.

Staurogyne alba caracteriza-se pelo caule ereto, raramente ramificado, com até $70 \mathrm{~cm}$ de altura, pela inflorescência terminal cilíndrica alongada e as axilares curtas, geralmente capituliformes, pela ausência de tricomas glandulosos na raque, brácteas e bractéolas, e raramente presentes no cálice, e pelas brácteas foliáceas. Embora ocorram nos estados do Paraná e Santa Catarina, S. eustachya Lindau e S. sylvatica Lindau ex D.M. Braz \& R. Monteiro diferem de $S$. alba, em especial, pelas inflorescências axilares alongadas, pela venação e dimensão das brácteas e pela presença de tricomas glandulosos nas diversas partes florais (tabela 1). Representantes herborizados de $S$. alba (Jonsson 833 e Dusén 6741) foram identificados por Lindau como $S$. eustachya, esta última uma espécie descrita pelo próprio Lindau (1897). Embora apresentem distribuição semelhante, com base no protólogo de $S$. eustachya e nos espécimes analisados de ambos os táxons, foi possível verificar inúmeras características diagnósticas não contempladas nos indivíduos de $S$. alba (tabela 1). O epíteto faz referência às flores brancas, não maculadas.

Staurogyne flava D.M. Braz \& R. Monteiro, sp. nov. Tipo: BRASIL. Minas Gerais: Sacramento, "Campo rupestre, beira de córrego, local sombreado. Flores tubulosas de cor amarela. Erva", 3-VIII-1984, R.C. Vieira \& N.M. Castro 288 (holótipo HUFU).

Figura 2

Ab omnibus speciebus generis pilis glandulosis ubique in tota planta, foliis ellipticis vel ellipticolanceolatis, membranaceis, racemo terminali pedunculato floribus laxis, corolla tubulosa flava differt.

Tabela 1. Características comparativas entre Staurogyne alba sp. nov., S. eustachya Lindau, S. mandioccana (Nees) Kuntze, $S$. riedeliana (Nees) Kuntze e $S$. sylvatica sp. nov., e distribuição geográfica nos estados brasileiros. $(\mathrm{BA}=\mathrm{Bahia}$; PR = Paraná; $\mathrm{MG}=$ Minas Gerais; RJ = Rio de Janeiro; $\mathrm{SC}=$ Santa Catarina; $\mathrm{SP}=$ São Paulo).

Table 1. Comparative features between Staurogyne alba sp. nov., S. eustachya Lindau, S. mandioccana (Nees) Kuntze, $S$. riedeliana (Nees) Kuntze and $S$. sylvatica sp. nov., and geographic distribution in Brazilian states. $(\mathrm{BA}=\mathrm{Bahia}$; $\mathrm{PR}=\mathrm{Paraná}$; $\mathrm{MG}=$ Minas Gerais; RJ = Rio de Janeiro; $\mathrm{SC}=$ Santa Catarina; SP = São Paulo).

\begin{tabular}{|c|c|c|c|c|c|}
\hline Caracteres & S. alba & S. sylvatica & S. eustachya & S. mandioccana & S. riedeliana \\
\hline Pecíolo - compr. (cm) & $1-3,1$ & $2,1-6,3$ & $1-4,0$ & $0,8-2,1$ & $0,7-1,2$ \\
\hline Lâmina foliar - compr. (cm) & $5,2-11,0$ & $6,8-14,6$ & $7,2-12,0$ & $6,5-11,9$ & $8-12,1$ \\
\hline larg. (cm) & $2-4,8$ & $3,3-6,7$ & $3,2-6,4$ & $1,9-3,6$ & $2,7-4,9$ \\
\hline $\begin{array}{l}\text { Inflorescência terminal } \\
\text { axilares }\end{array}$ & $\begin{array}{l}\text { cilíndrica ou } \\
\text { subcapitada }\end{array}$ & piramidal & cilíndrica & subpiramidal & $\begin{array}{l}\text { piramidal ou } \\
\text { subcapitada }\end{array}$ \\
\hline & até a $4^{\mathrm{a}}$ axila & até a $4^{\mathrm{a}}$ axila & até a $5^{\mathrm{a}}$ axila & até a $2^{\mathrm{a}}$ axila & até a $2^{\mathrm{a}}$ axila \\
\hline Brácteas & foliáceas & petalóides & foliáceas & petalóides & foliáceas \\
\hline dimensões (mm) & $5-11,7 \times 2-6,5$ & $3,8-7,0 \times 0,8-2,8$ & $4,7-8,5 \times 1,5-3,0$ & $5,5-9,5 \times 3,3-5,6$ & $9,5-10,1 \times 3,5-5,0$ \\
\hline forma & $\begin{array}{c}\text { elíptica a } \\
\text { elíptico-ovada }\end{array}$ & $\begin{array}{l}\text { elíptica a } \\
\text { lanceolado- }\end{array}$ & $\begin{array}{c}\text { oblonga a } \\
\text { oblongo-elíptica }\end{array}$ & $\begin{array}{c}\text { elíptica a } \\
\text { suborbicular }\end{array}$ & $\begin{array}{l}\text { elíptica a } \\
\text { subobovada }\end{array}$ \\
\hline venação & 1-nérveas & 3 acródromas & 3-nérveas & 3 acródromas & 3 acródromas \\
\hline Pedicelo - compr. & $1-1,8 \mathrm{~mm}$ & $1,5-4,0 \mathrm{~mm}$ & ausente & $0,3-1,2 \mathrm{~mm}$ & ausente \\
\hline $\begin{array}{l}\mathrm{N}^{o} \text { nervuras segmento } \\
\text { posterior do cálice }\end{array}$ & (3) 5 & (3) $5-7$ & 3 & 3 & 3 \\
\hline Corola - compr. (mm) & $10,4-15,2$ & $10-16,5$ & $9-12,8$ & $7,8-10,3$ & $11,5-12,1$ \\
\hline Tricomas glandulosos & corola, fruto & $\begin{array}{l}\text { raque, bráctea, } \\
\text { bractéola, cálice, } \\
\text { corola, fruto }\end{array}$ & $\begin{array}{l}\text { raque, bráctea, } \\
\text { bractéola, cálice, } \\
\text { corola, fruto }\end{array}$ & $\begin{array}{l}\text { cálice, corola, } \\
\text { fruto }\end{array}$ & $\begin{array}{c}\text { raque, bráctea, } \\
\text { bractéola, cálice, } \\
\text { corola, fruto }\end{array}$ \\
\hline Distribuição geográfica & PR, SC & PR, RJ, SC, SP & PR, SC & RJ & $\mathrm{BA}, \mathrm{MG}, \mathrm{RJ}$ \\
\hline
\end{tabular}


Ervas a subarbustos, até $80 \mathrm{~cm}$ alt., caule raramente ramificado, esparso-piloso, com tricomas simples e glandulosos. Pecíolo 0,6-1,5 cm; lâmina 5,3-12,0 × 1,8-4,2 cm, elíptica a lanceolado-elíptica, ápice agudo, base geralmente aguda, membranácea, com tricomas simples e glandulosos esparsos em ambas as faces, raramente restritos às nervuras. Inflorescência racemo terminal subpiramidal, raramente paniculiforme, com flores laxas, 3,0-15,0 cm compr., pedúnculo 1,5-3,0 cm compr., com tricomas glandulosos esparsos na raque; brácteas e bractéolas verde-amareladas, externamente com tricomas glandulosos esparsos, bráctea 5,0-12,0 $\times$ 2,0-4,0 mm, elíptica a subromboidal, ápice e base agudos, 1-3-nérvea; bractéolas 3,0-10,0 × 1,0-1,7 mm, lanceoladas a oblongo-obovadas, ápice agudo a obtuso, base aguda a cuneada, inseridas a 4,0-5,0 $(8,0) \mathrm{mm}$ da base do pedicelo. Pedicelo 4,0-8,0(10,0) mm compr.; cálice amarelo a amarelo-esverdeado, externamente com tricomas glandulosos esparsos, segmento posterior $11,0-17,0(20,0) \times 1,7-5,0 \mathrm{~mm}$, oblongo, raramente lanceolado-elíptico, ápice agudo, 3-nérveo, par lateral 6,5-12,0 $\times 0,3-0,8 \mathrm{~mm}$, subulado, par anterior 10,0-14,0 $\times$ 1,0-2,0 mm, oblongo, raramente oblongo-lanceolado; corola tubulosa, amarela, 23,0-37,0(43,0) mm compr., 4,0-6,0 mm diâm. na garganta, lobos 2,0-4,2 mm compr., oblongos a suborbiculares, ápice obtuso, com tricomas glandulosos esparsos a subdensos externamente, glabros internamente; estames anteriores 18,0-28,0(35,0) $\mathrm{mm}$ compr., posteriores 16,0-27,0(32,0) $\mathrm{mm}$, glabros; estaminódio 2,0-5,0 mm compr., sigmóide, raramente ereto, ápice geralmente dilatado, inserido na mesma altura dos estames posteriores; anteras com tecas oblongas a reniformes, conectivo geralmente dilatado, 1,0-1,5 mm compr.; óvulos 23-34 por lóculo; estilete 29,0-35,0 mm compr., lobo posterior do estigma côncavo, a bipartido, 0,5-1,3 mm compr., anterior 0,7-1,5 mm, elíptico, raramente oblongo. Cápsula cilíndrica, raramente subclavada, $8,0-15 \times 2,0-3,5 \mathrm{~mm}$, externamente com tricomas glandulosos esparsos; sementes 23-34 por valva.

Material adicional examinado: BRASIL. DISTRITO Federal: Brasília, Parque Municipal do Gama, 28-VIII-1965, H.S. Irwin et al. 7921 (RB, F, K, SP). GoiÁs: Caldas Novas, Serra de Caldas, 10-VII-1976, G. Hatschbach 38790 (C, HB, MBM); Caldas Novas, Serra de Caldas, 11-VI-1996, T.B. Cavalcante et al. 1978 (SPF). Minas Gerais: Prados, 7-VII-1991, J.R. Stehmann s.n. (BHCB 21500, SPF 100245).

Staurogyne flava apresenta distribuição relativamente ampla, ocorrendo no Planalto Central

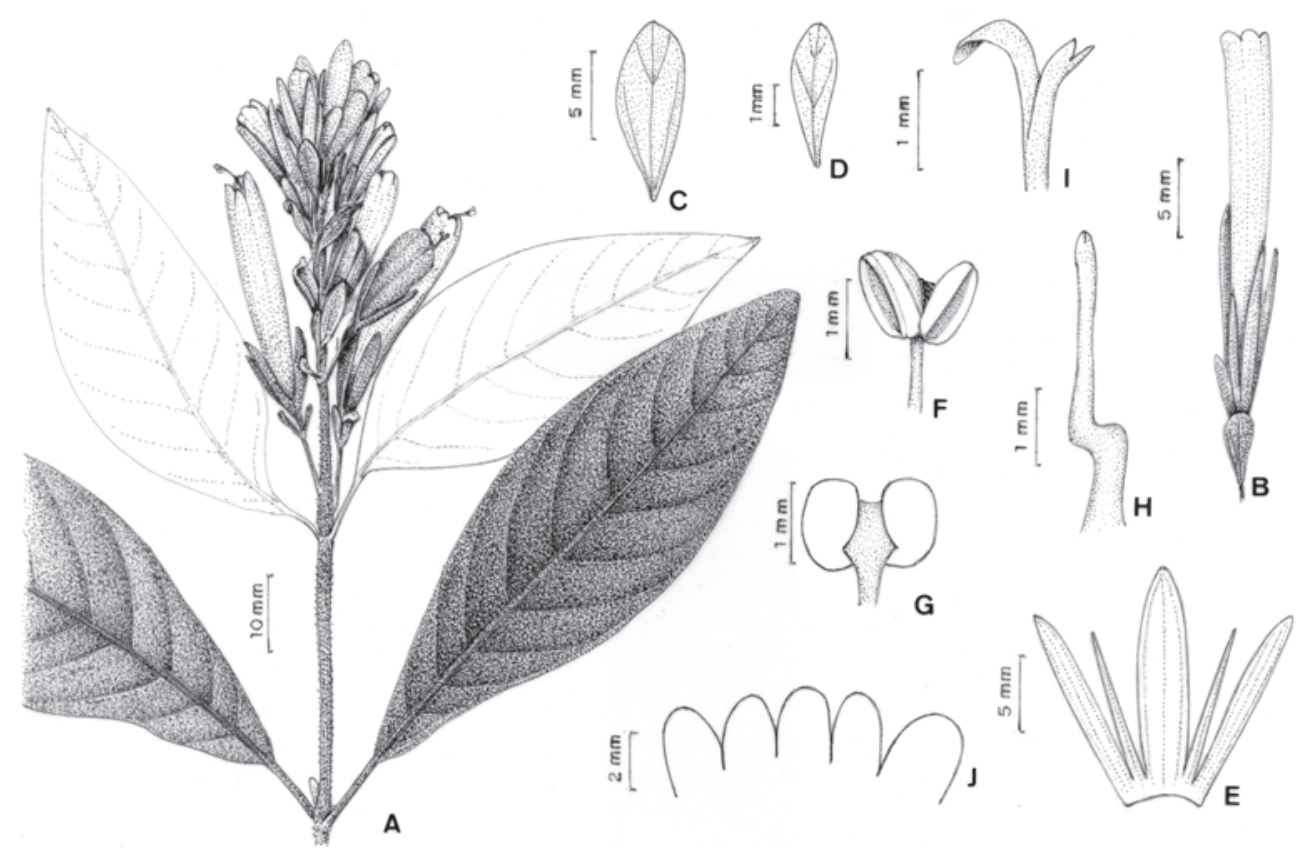

Figura 2. Staurogyne flava D.M. Braz \& R. Monteiro. A. Ramo florido. B. Flor isolada. C. Bráctea. D. Bractéola. E. Cálice seccionado em vista externa. F. Antera em vista frontal. G. Antera em vista dorsal. H. Estaminódio. I. Estigma em vista lateral. J. Lobos da corola aberta. (A, E-J - Vieira \& Castro 288; B-D - Cavalcante et al. 1978).

Figure 2. Staurogyne flava D.M. Braz \& R. Monteiro. A. Flowering stem. B. Flower. C. Bract. D. Bracteole. E. Open calyx in external view. F. Anther in frontal view. G. Anther in dorsal view. H. Staminode. I. Stigma in lateral view. J. Open corolla lobes. (A, E-J - Vieira \& Castro 288; B-D - Cavalcante et al. 1978). 
brasileiro e em diversas serras mais ou menos isoladas, desde Brasília até o sul-sudoeste de Minas Gerais, geralmente acima dos $600 \mathrm{~m}$ de altitude. É uma planta rupestre, encontrada em lugares sombreados, úmidos e à beira de rios, nas matas de galeria. S. flava foi coletada com flores praticamente ao longo de todo o ano, mas principalmente entre os meses de maio a agosto, e com frutos entre julho e agosto.

Representantes de Staurogyne flava são reconhecidos pelos tricomas glandulosos presentes em toda a planta, pelos ramos delgados, as folhas elípticas a lanceolado-elípticas, membranáceas, as brácteas elípticas a subromboidais, e pelas flores laxas, longopediceladas e com corola tubulosa amarela. S. flava é próxima a $S$. hirsuta (Nees) Kuntze e $S$. ericoides Lindau pela pilosidade glandulosa em toda a planta e pelas brácteas e bractéolas geralmente verdes, diferindo destas, principalmente, pelas dimensões, forma e consistência das folhas (tabela 2). Representantes de S. flava têm sido, com freqüência, erroneamente identificados como $S$. anigozanthus (Nees) Kuntze, mas essa espécie é totalmente distinta pela ausência de tricomas glandulosos nas partes vegetativas, entre diversos outros aspectos. Essa confusão talvez seja explicada pela descrição sucinta de $S$. anigozanthus e pelas consultas escassas ao tipo, depositado no Herbário LE, na Rússia. O epíteto de $S$. flava refere-se às flores com corola amarela.

Staurogyne parva D.M. Braz \& R. Monteiro, sp. nov. Tipo: BRASIL. Espírito SAnto: Santa Tereza, Nova Lombardia, "erva em semi-sombra, em local com muita matéria orgânica, pilosidade branca e vinácea",
15-V-1985, H.Q.B. Fernandes 1142 (holótipo MBML). Figura 3

Ab omnibus speciebus generis pilis glandulosis bracteis, bracteoleis, calyce, corolla et fructu ornatis, foliis magnis $(5,8-11,5 \times 1,8-3,4 \mathrm{~mm})$, lanceolatis vel lanceolato-ellipticis, petiolo longo (9-33 mm), inflorescentia terminali elongata, bracteis foliaceis, ciliatis, corolla infundibuliformi elongata (9,3-15 mm longa), ovulis/semenibus 6-7 per loculum/valvam differt.

Ervas, às vezes subarbustos, $20-40,0 \mathrm{~cm}$ alt., caule geralmente ramificado na base, com tricomas simples adensados em direção ao ápice. Pecíolo $0,9-3,3 \mathrm{~cm}$ compr.; lâmina 5,8-11,5 × 1,8-3,4 cm, lanceolada a lanceolado-elíptica, às vezes subovada, ápice agudo, base aguda a cuneada, membranácea a subcartácea, com tricomas simples esparsos em ambas as faces. Inflorescência racemo espiciforme terminal cilíndrico, com flores congestas, 2,5-13,5 cm compr., pedúnculo até $0,8 \mathrm{~cm}$ compr., com tricomas simples densos na raque; brácteas e bractéolas foliáceas, externamente com tricomas simples e glandulosos esparsos, às vezes ciliadas, bráctea 9,0-12,5 × 4,5-7,0 mm, elíptica a suborbicular, ápice agudo, base aguda a cuneada, 3-nérvea; bractéolas 5,7-8,0 × 0,8-1,5 mm, lanceoladas a lanceolado-elípticas, ápice e base agudos. Pedicelo até $1,5 \mathrm{~mm}$ compr.; cálice verde, externamente com tricomas simples e glandulosos esparsos, às vezes ciliado, segmento posterior 8,5-11,5 × 2,0-3,3 mm, oblongoelíptico a lanceolado-elíptico, ápice agudo, 3-nérveo, par lateral 5,0-9,0 × 0,3-0,8 mm, subulado, par anterior 8,7-12,0 × 1,0-1,6 mm, oblongo a oblongo-lanceolado;

Tabela 2. Características comparativas entre Staurogyne flava sp. nov., S. ericoides Lindau e S. hirsuta (Nees) Kuntze, e distribuição geográfica nos estados brasileiros. $(\mathrm{DF}=$ Distrito Federal; $\mathrm{GO}=$ Goiás; $\mathrm{MG}=$ Minas Gerais $)$.

Table 2. Comparative features between Staurogyne flava sp. nov., S. ericoides Lindau and S. hirsuta (Nees) Kuntze, and geographic distribution in Brazilian states. ( $\mathrm{DF}=$ Distrito Federal; $\mathrm{GO}=$ Goiás; $\mathrm{MG}=$ Minas Gerais).

\begin{tabular}{lccc}
\hline Caracteres & S. flava & S. ericoides & S. hirsuta \\
\hline Pilosidade nos ramos e folhas & esparsa & densa & densa \\
Lâmina foliar - forma & elíptica a lanceolado-elíptica & lanceolada & elíptica a lanceolado-elíptica \\
dimensões $(\mathrm{cm})$ & $5,3-12,0 \times 1,8-4,2$ & $1,8-6,0 \times 0,5-1,3$ & $3,5-7,9 \times 0,9-2,2$ \\
consistência & membranácea & cartácea & cartácea \\
Racemo terminal & pedunculado & séssil & séssil \\
Flores & laxas & laxas & congestas \\
Brácteas $(\mathrm{mm})$ & $5-12,0 \times 2-4,0$ & $18-60,0 \times 0,5-1,3$ & $10-35,0 \times 4,5-11,0$ \\
Segmentos laterais cálice $(\mathrm{mm})$ - compr. & $6,5-12,0$ & $9,3-12,9$ & $10,2-16,0$ \\
Segmentos anteriores cálice $(\mathrm{mm})$ - compr. & $10-14,0$ & $9,7-15,0$ & $13-21,0$ \\
Distribuição geográfica & DF, GO,MG & MG & MG \\
\hline
\end{tabular}


corola infundibuliforme, branca com mácula vinácea na abertura da garganta e na base dos lobos, 9,3-15,0 mm compr., 2,0-3,5 mm diâm. na garganta, lobos posteriores e laterais 1,5-4,0 mm compr., oblongos a oblongoelípticos, anterior 2,1-4,5 mm compr., oblongo-elíptico, ápice obtuso, com tricomas simples esparsos externamente e internamente; estames anteriores 4,5-5,8 mm compr., posteriores 4,0-5,4 $\mathrm{mm}$, glabros, estaminódio 1,0-3,5 mm compr., ereto, ápice dilatado, inserido acima dos estames posteriores; anteras com tecas reniformes, conectivo dilatado, $0,5-1,0 \mathrm{~mm}$ compr.; óvulos 6-7 por lóculo; estilete 4,8-8,8 mm compr., lobo posterior do estigma bipartido, 0,5-0,8 $\mathrm{mm}$ compr., anterior 0,6-0,9 mm compr., oblongo. Cápsula subcônica, $6,5-7,0 \times 3,2-3,8 \mathrm{~mm}$, externamente com tricomas glandulosos esparsos; sementes 6-7 por valva.

Material adicional examinado: BRASIL. EsPíRITO SAnto: Santa Tereza, Nova Lombardia, Goipaboaçu, 2-XII-1985, W. Boone 927 (MBML); Santa Tereza, Valsugana Velha, Estação Biológica de Santa Lúcia, $19^{\circ} 58^{\prime}$ S, 40³2' W, 21-IX-1989, H.Q.B. Fernandes 2862 (MBML).

Staurogyne parva é encontrada em locais semisombreados, com muita matéria orgânica (Fernandes
1142). Ocorre no Estado do Espírito Santo desde a floresta pluvial baixo-montana (300-400 $\mathrm{m}$ alt.) até a floresta pluvial montana em altitudes de cerca de 700$850 \mathrm{~m}$, às margens de rios. Foi coletada com flores em maio e flores e frutos em dezembro.

Staurogyne parva caracteriza-se pelo porte pequeno (até $40 \mathrm{~cm}$ de altura), pelas folhas lanceoladas a lanceolado-elípticas, pilosas em ambas as faces, a inflorescência terminal alongada, com brácteas foliáceas, elípticas a suborbiculares, ciliadas, a corola infundibuliforme e, especialmente, pelo número reduzido de óvulos por lóculo (6-7). Quanto ao porte reduzido, à inflorescência terminal alongada e às brácteas foliáceas, $S$. parva é semelhante a $S$. euryphylla E. Hossain, diferindo principalmente pelas dimensões e forma das folhas, pelas flores bem menores e pelos óvulos mais numerosos nesta última (tabela 3 ). O epíteto específico é uma alusão ao hábito pequeno.

Staurogyne sylvatica Lindau ex D.M. Braz \& R. Monteiro, sp. nov. Tipo: BRASIL. Rio De JANEIRo: Parati, Fazenda São Roque, "c. de 600 m.s.m.. Flor lilás com estrias arroxeadas. Arbusto $1 \mathrm{~m}$. Brácteas esverdeadas", 4-VIII-1988, M.C. Marques 106 (holótipo RB).

Figura 4
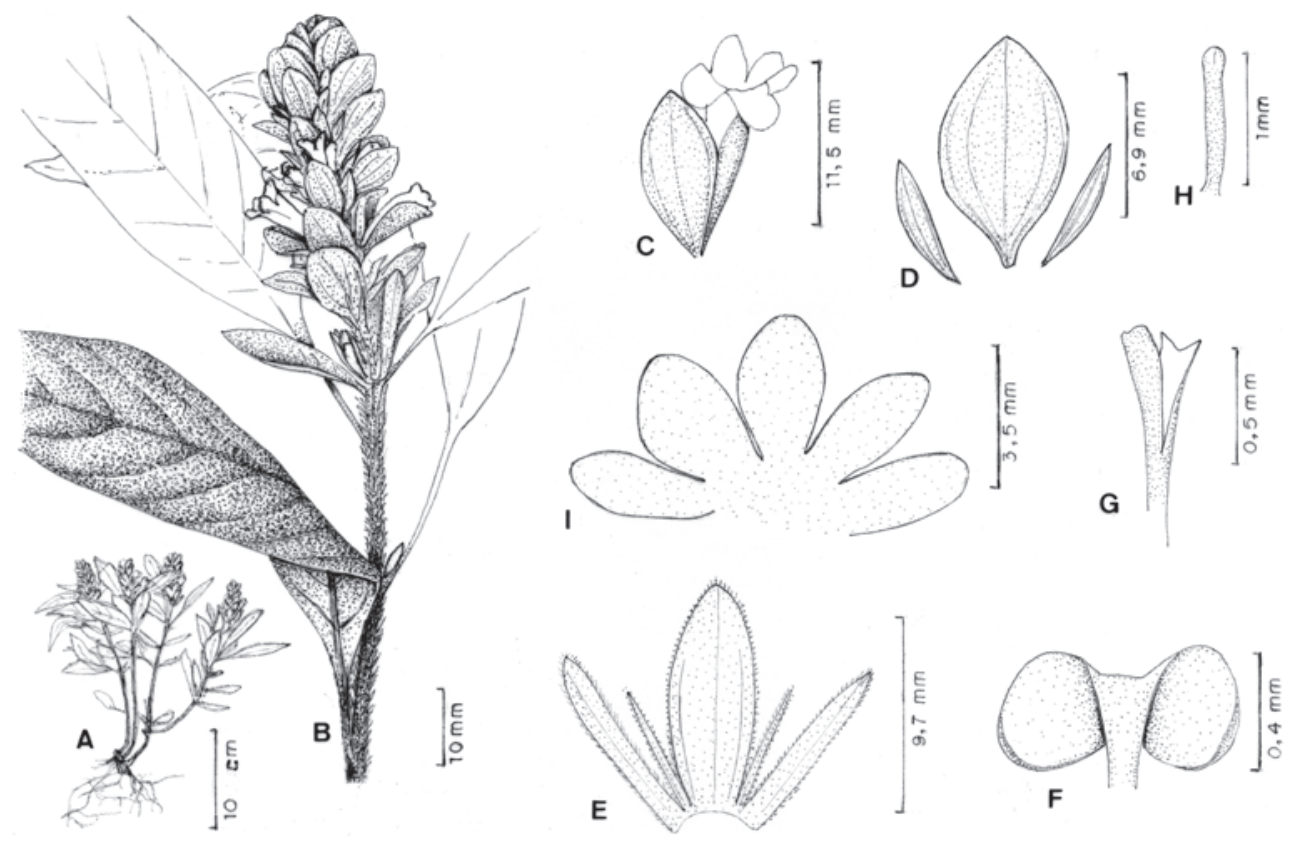

Figura 3. Staurogyne parva D.M. Braz \& R. Monteiro. A. Hábito. B. Ramo florido. C. Flor isolada. D. Bráctea e bractéolas. E. Cálice seccionado em vista externa. F. Antera em vista dorsal. G. Estigma em vista lateral. H. Estaminódio. I. Lobos da corola aberta. (A-I - Fernandes 2862).

Figure 3. Staurogyne parva D.M. Braz \& R. Monteiro. A. Habit. B. Flowering stem. C. Flower. D. Bract and bracteoles. E. Open calyx in external view. F. Anther in dorsal view. G. Stigma in lateral view. H. Staminode. I. Open corolla lobes. (A-I - Fernandes 2862). 
Ab omnibus speciebus generis pilis glandulosis ubique organorum reproductiviorum, follis magnis (6,8-14,6 × 3,3-6,7 mm), longo-peciolatis (2,1-6,3 cm compr.), petiolis elongatis (2,1-6,3 cm compr.), inflorescentiis pyramidalibus, axillaribus minoribus, bracteis petaloideis ellipticis vel lanceolato-ellipticis venis acrodromis, parvis $(3,8-7 \mathrm{~mm}$ longa), floribus pedicello 1,5-4 $\mathrm{mm}$ longo et corolla infundibuliformi 10-16,5 mm longa differt.

Subarbustos eretos, 0,2-1,0 m alt., caule geralmente ramificado, com tricomas simples esparsos. Pecíolo 2,1-6,3 cm compr.; lâmina 6,8-14,6 × 3,3-6,7 cm, elíptica, ovado-elíptica a elíptico-lanceolada, ápice agudo a acuminado, base cuneada a abruptamente cuneada, membranácea a subcartácea, face adaxial glabra, raramente com tricomas simples na nervura central, na abaxial restritos às nervuras. Inflorescência racemo espiciforme terminal e até 4 pares axilares, piramidais, com flores geralmente laxas, terminal 4,0-7,3 cm compr., axilares 1,0-3,5 cm compr., pedúnculo 0,3-1,9 cm compr., raque com tricomas simples e glandulosos esparsos; brácteas e bractéolas petalóides, amareloesbranquiçadas a esverdeadas, externamente com tricomas simples e glandulosos esparsos, bráctea 3,8-6,5(7,0) × 0,8-2,8 mm, elíptica a lanceolado-elíptica, ápice e base agudos, 3 nervuras acródromas; bractéolas $3,0-6,2 \times 0,5-1,0 \mathrm{~mm}$, linear-lanceoladas, às vezes obovada, ápice e base agudos, inseridas $0,7-1,5 \mathrm{~mm}$ da base do pedicelo. Pedicelo 1,5-4,0 mm compr.; cálice verde-esbranquiçado, externamente com tricomas simples e glandulosos esparsos, segmento posterior 9,0-13,6 × 2,8-5,3 mm, elíptico a oblongo-elíptico, às vezes subobovado, ápice agudo a subobtuso, (3)5-7-nérveo, par lateral 6,0-9,8 $\times 0,5-1,0 \mathrm{~mm}$, subulado a linear, par anterior 7,7-12,2 $\times 0,9-1,9 \mathrm{~mm}$, oblongo a oblongolanceolado; corola infundibuliforme, branca a lilás, com mácula vinácea na abertura da garganta, $10,0-16,5 \mathrm{~mm}$ compr., 3,3-5,0 mm diâm. na garganta, lobos posteriores 2,0-4,5 mm compr., laterais 2,9-5,0 mm, geralmente oblongos, anterior $3,5-5,1 \mathrm{~mm}$, suborbicular a subobovado, ápice obtuso, tricomas simples e glandulosos esparsos externamente, glabros internamente; estames anteriores 3,8-6,0 mm compr., posteriores $3,8-5,5 \mathrm{~mm}$, com tricomas glandulosos raros, estaminódio 0,9-2,0 mm compr., ereto, ápice dilatado, inserido geralmente abaixo dos estames; anteras com tecas suborbiculares a reniformes, conectivo geralmente dilatado, 0,7-1,1 mm compr.; óvulos 13-22 por lóculo; estilete $6,0-8,5 \mathrm{~mm}$ compr., lobo posterior do estigma truncado a côncavo, raramente bipartido, $0,4-0,8 \mathrm{~mm}$ compr., anterior 0,6-1,2 mm compr., oblongo. Cápsula cilíndrico-ovada, 7,0-10,0 × 2,0-4,0 mm, externamente com tricomas glandulosos; sementes 13-22 por valva.

Material adicional examinado: BRASIL. PARANÁ: Paranaguá, Mananciais da Serra, 20-VIII-1968, G. Hatschbach 19621 (C, MBM). Santa Catarina: Ilhota, Parque Botânico Morro do Baú, 1-X-1989, D.B. Falkenberg 4838 (MBM). São Paulo: Juquiá, 2406'19" S, 47037'29" W, 9-IX-1994, E. Moncaio et al. EM-31 (HRCB, ESA, SPF, UEC); Tapiraí, Rodovia 79, 11-V-1994, R. Mello-Silva et al. 893 (HRCB, K, UEC).

Staurogyne sylvatica ocorre no Sul do Estado do Rio de Janeiro, estendendo-se pelos Estados de São Paulo, Paraná até Santa Catarina, geralmente em altitudes acima dos $500 \mathrm{~m}$. Seus representantes são encontrados geralmente em locais úmidos, no interior ou beira da

Tabela 3. Características comparativas entre Staurogyne parva sp. nov. e S. euryphylla E. Hossain, e distribuição geográfica nos estados brasileiros. (ES = Espírito Santo; RJ = Rio de Janeiro).

Table 3. Comparative features between Staurogyne parva sp. nov. and S. euryphylla E. Hossain, and geographic distribution in Brazilian states. (ES = Espírito Santo; RJ = Rio de Janeiro).

\begin{tabular}{lcc}
\hline Caracteres & S. parva & S. euryphylla \\
\hline Pilosidade nos ramos & densa & esparsa \\
Pecíolo - compr. (cm) & $0,9-3,3$ & $0,2-0,8$ \\
Lâmina foliar (cm) & $5,8-11,5 \times 1,8-3,4$ & $1,9-5,0 \times 1-2,0$ \\
Inflorescência & terminal & terminal e axilar \\
Segmentos laterais do cálice - compr. (mm) & $5-9,0$ & $3,8-5,1$ \\
Segmentos anteriores do cálice - compr. (mm) & $8,7-12,0$ & $5,8-6,1$ \\
Corola & maculada & não maculada \\
Brácteas - compr. (mm) & $9-12,5$ & $4,9-8,9$ \\
Número de óvulos por lóculo & $6-7$ & $13-15$ \\
Distribuição geográfica & ES & RJ \\
\hline
\end{tabular}




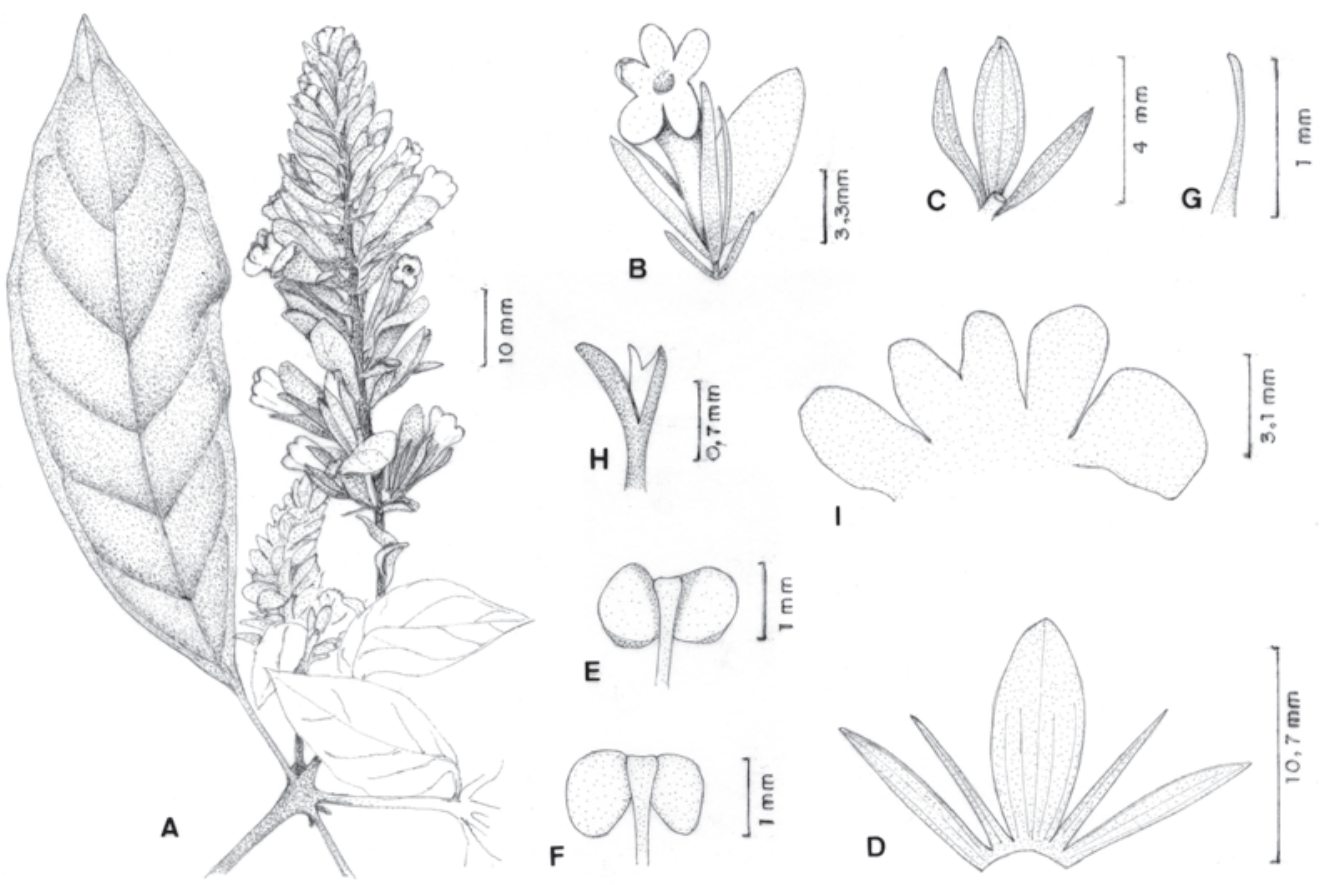

Figura 4. Staurogyne sylvatica Lindau ex D.M. Braz \& R. Monteiro. A. Ramo florido. B. Flor isolada. C. Bráctea e bractéolas. D. Cálice seccionado em vista externa. E. Antera em vista frontal. F. Antera em vista dorsal. G. Estaminódio. H. Estigma em vista lateral. I. Lobos da corola aberta (A-F, I - Marques 106; G-H - Falkenberg 4838).

Figure 4. Staurogyne sylvatica Lindau ex D.M. Braz \& R. Monteiro. A. Flowering stem. B. Flower. C. Bract and bracteoles. D. Open calyx in external view. E. Anther in frontal view. F. Anther in dorsal view. G. Staminode. H. Stigma in lateral view. I. Open corolla lobes (A-F, I - Marques 106; G-H - Falkenberg 4838).

Floresta Pluvial Atlântica. Floresce e frutifica praticamente o ano todo, mas principalmente entre agosto e outubro.

Staurogyne sylvatica é um subarbusto delicado com até $1 \mathrm{~m}$ de altura, reconhecido principalmente pelas folhas longo-pecioladas, as inflorescências piramidais, com brácteas petalóides, elípticas a lanceolado-elípticas, com venação acródroma, bem menores que as flores, $o$ segmento posterior do cálice geralmente 5-7-nérveo e a corola infundibuliforme relativamente longa (10-16,5 $\mathrm{mm}$ compr.). É próxima a $S$. mandioccana (Nees) Kuntze e $S$. riedeliana (Nees) Kuntze especialmente pelas brácteas com venação acródroma e pela forma da corola, mas diferem pelas folhas curto-pecioladas e as flores sésseis a subsésseis nessas duas espécies (tabela 1). S. sylvatica é semelhante a $S$. alba e $S$. eustachya no hábito, na forma e dimensões foliares e na forma da corola. Esses táxons, que igualmente ocorrem nos Estados do Paraná e Santa Catarina, diferem de $S$. sylvatica, em especial, pelas brácteas foliáceas, com venação distinta e aproximadamente do mesmo tamanho das flores (tabela 1). O epíteto específico já havia sido utilizado por Lindau em etiquetas de exsicatas (Loefgren \& Edwall 1617; Edwall 1891, ambas depositadas em C), porém nunca foi devidamente publicado, e como a espécie ocorre na Mata Atlântica, o epíteto foi mantido.

Agradecimentos - Os autores agradecem à Fapesp pela bolsa de doutorado concedida à primeira autora; ao Dr. Dieter Wasshausen pela ajuda na localização dos tipos das espécies já descritas; aos Dr. Tarciso Filgueiras e Dra. Cíntia Kameyama pelas correções no latim e leitura do manuscrito; a Jaime Roberto Somera pelas ilustrações das espécies; e aos curadores dos herbários brasileiros e estrangeiros pelo empréstimo das coleções.

\section{Referências bibliográficas}

BRAZ, D.M. \& MONTEIRO, R. 2005. Staurogyne rubescens (Acanthaceae): a new species from southeastern Brazil. Novon 15:55-58.

CHAMPLUVIER, D. 1991. Révision des genres Staurogyne Wall., Anisosepalum E. Hossain et Saintpauliopsis Staner (Acanthaceae) en Afrique tropicale. Bulletin du Jardin Botanique National de Belgique 61:93-159.

LINDAU, G.B. 1897. Acanthaceae americanae et asiaticae. Bulletin de L'Herbier Boissier 5:643-681. 